\title{
Evaluation of the result of single-incision laparoscopic surgery for gastrointestinal stromal tumors in the stomach
}

\author{
Takashi Tatara* (D), Shingo Kanaji, Satoshi Suzuki, Ryo Ishida, Hiroshi Hasegawa, Masashi Yamamoto, \\ Yoshiko Matsuda, Kimihiro Yamashita, Taro Oshikiri, Takeru Matsuda, Tetsu Nakamura, Yasuo Sumi and \\ Yoshihiro Kakeji
}

\begin{abstract}
Background: Single-incision laparoscopic surgery (SILS) has recently been used for the management of gastrointestinal stromal tumors (GIST). Here, the feasibility and effectiveness of SILS for GIST and indications for SILS according to tumor location were investigated.

Case presentation: From July 2009 to May to 2013, a total of 14 patients underwent SILS for GIST. In 14 patients, 5 patients had tumor near the esophagogastric junction, 4 patients on the lesser curvature, 2 patients on the anterior wall, 2 patients on the posterior wall, and 1 patient on the greater curvature. The surgery of one patient with lesser curvature tumor was converted to conventional laparoscopic surgery because of technical difficulties. Another patient required re-operation because of a posterior wall tumor causing gastric obstruction. There was no complication in patients with tumors on the anterior wall and greater curvature.

Conclusions: Because SILS for GISTs located mainly on the anterior wall was feasible, SILS may be considered the most appropriate type of laparoscopic surgery for GISTs in this location. However, for GISTs on the posterior wall or with lesser curvature, which require more complex management, SILS is challenging and should be carefully adapted.
\end{abstract}

Keywords: Submucosal tumor, Gastrointestinal stromal tumor, Laparoscopic gastric resection, Single-incision laparoscopic surgery, Tumor location

\section{Background}

Since the development of endoscopic ultrasonography and fine-needle aspiration, gastric submucosal tumors (SMTs), including asymptomatic tumors of less than $1 \mathrm{~cm}$, have been more frequently detected. Gastrointestinal stromal tumors (GISTs) are potentially malignant tumors, which are often treated by surgical resection. Because GISTs rarely involve the lymph node and require a resection margin that is only grossly negative, laparoscopic gastric resection has become an acceptable option [1,2]. The National Comprehensive Cancer Network and the Japanese Clinical Practice Guidelines on GIST recommend that laparoscopic resection, conducted by an expert laparoscopic surgeon, may be suitable for tumors of $5 \mathrm{~cm}$ or less in diameter [3, 4]. Furthermore, the use of single-incision laparoscopic surgery (SILS) for GISTs has recently become more common $[5,6]$. However, there are only few reports describing SILS for GISTs, in particular, modification of the SILS procedure depending on tumor location [7].

Previously, we demonstrated that laparoscopic surgery was effective for SMTs adjacent to the esophagogastric junction (EGJ) [8]. In this study, the feasibility and effectiveness of SILS for GISTs was evaluated, and the need to adapt SILS according to tumor location is discussed.

\footnotetext{
* Correspondence: tatara@med.kobe-u.ac.jp

Division of Gastrointestinal Surgery, Department of Surgery, Graduate School of Medicine, Kobe University, 7-5-2 Kusunoki-cho, Chuo-ku, Kobe, Hyogo 650-0017, Japan
} 


\section{Case presentation Patients}

A retrospective review was performed using data from 14 patients who underwent SILS for GIST at Kobe University Hospital between July 2009 and May 2013. The indicative criterion for laparoscopic surgery was a lesion diameter of less than $5 \mathrm{~cm}$. Patients' background characteristics and surgical, clinicopathological, and follow-up data were collected from medical records. All patients were operated by endoscopic surgical skill qualification system of the Japan Society of Endoscopic Surgery qualified surgeons. This study was approved by the Institutional Review Board of Kobe University.

\section{Procedural techniques for SILS}

During SILS, the surgeon stood between the legs of the patient. A round or oval Lap Protector device (Hakko Co. Ltd., Tokyo, Japan) was placed through a single 25-mm longitudinal umbilical incision, and a round or oval E.Z Access device (Hakko Co. Ltd) was placed over the Lap Protector. A 5-mm trocar was then inserted laterally to the left, and a 12-mm trocar was inserted to the right, into the E.Z Access device. A 5-mm flexible scope was inserted through the $5-\mathrm{mm}$ trocar at the extreme caudal position of the E.Z Access port for the duration of the procedure. In all patients, intraoperative endoscope was used, the linear stapler was used for both resection and suture, and extraluminal approach and open type resection was performed. To keep the operative field, we constructed the following devices. A suture was placed across the gastric wall at the anal side of the tumor, and the thread was pulled out from the abdominal cavity to enhance the operative field. A second method to prevent the liver obscuring the operating field was to raise the left lateral segment of the liver with a narrow retracting device (Fig. 1).

\section{Patient characteristics and operative outcomes}

The characteristics and operative outcomes of the study population are summarized in Table 1. A total of 14 patients underwent SILS for GIST. In 14 patients, 5 patients had tumor near the esophagogastric junction (EGJ), 4 patients on the lesser curvature, 2 patients on the anterior wall, 2 patients on the posterior wall, and 1 patient on the greater curvature. The term "located near the EG)" was defined as "within $3 \mathrm{~cm}$ of the EGJ based on the preoperative endoscopic measurement". The surgery of one patient with lesser curvature GIST was converted to conventional laparoscopic surgery due to technical difficulties. One patient who had a tumor on the posterior wall developed gastric obstruction and required distal gastrectomy. No complications were reported in patients who had a tumor on the anterior wall or greater curvature. There were no recurrences in the follow-up period.

\section{Discussion}

We reported the outcomes of 14 patients who underwent SILS for GIST.

In our reports, though all patients were operated by endoscopic surgical skill qualification system of Japan Society of Endoscopic Surgery qualified surgeons, operative time was longer than other reports from Japan and other countries [6,7]. Recent development of surgical devices such as the three-dimensional monitor and linear stapler may enable us to shorten the operative time.

SILS has some advantages such as better cosmetic outcomes because the use of trans-abdominal ports results in fewer wounds. The cosmetic benefit of SILS for GIST resections, which leaves only a single umbilical scar, may increase patient satisfaction $[9,10]$. Deveci et al. reported that patients who underwent SILS for cholecystectomy had higher cosmetic satisfaction relative to those who underwent laparoscopic surgery involving three ports [11]. Furthermore, Ceci et al. reported that SILS for appendectomy was associated with a lower risk of postoperative wound infection [12]. Considering the effectiveness of SILS, it has the potential to become the first choice for GISTs, providing that technical difficulties are surmounted.
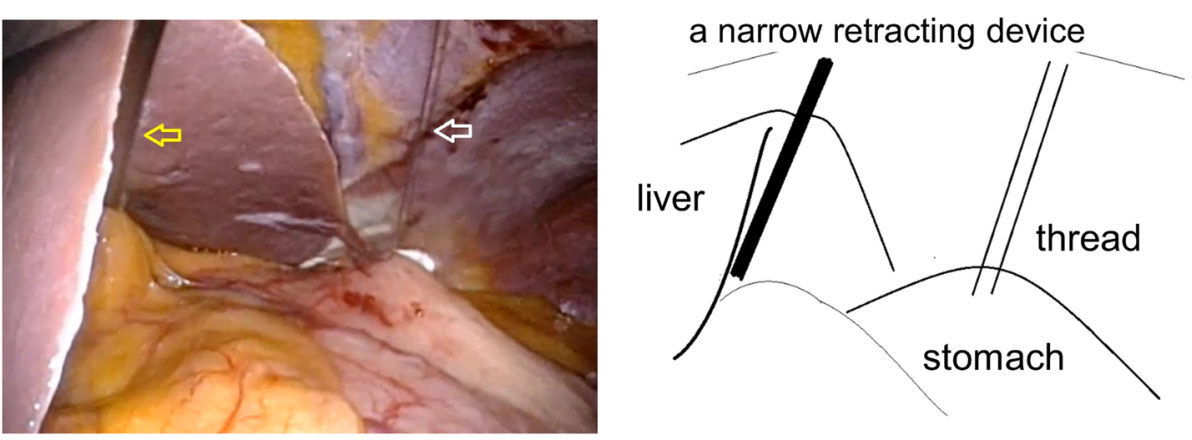

Fig. 1 The way of our keeping the operative field. A suture was placed across the gastric wall at the anal side of the tumor, and the thread was pulled out from the abdominal cavity (white arrow). The left lateral segment of the liver was elevated with a narrow retracting device (yellow arrow). 
Table 1 Characteristics and surgical outcomes of patients

\begin{tabular}{|c|c|c|c|c|c|c|c|c|}
\hline Age (years) & Sex & Year of operation & BMl & Tumor size (mm) & Location & Developmental pattern & Operative time (min) & Complication \\
\hline 68 & M & 2009 & 20.6 & 30 & Pos & Extra & 192 & Non \\
\hline 70 & $\mathrm{~F}$ & 2009 & 17.9 & 33 & NEJ & Intra & 191 & Non \\
\hline 67 & M & 2010 & 31 & 40 & NEJ & Intra & 189 & Non \\
\hline 50 & $\mathrm{~F}$ & 2010 & 20.3 & 37 & NEJ & Intra & 195 & Non \\
\hline 57 & M & 2010 & 27.2 & 27 & Gre & Extra & 125 & Non \\
\hline 49 & $\mathrm{~F}$ & 2010 & 19.5 & 35 & Les & Extra & 102 & Non \\
\hline 54 & $\mathrm{~F}$ & 2010 & 23.8 & 30 & NEJ & Intra & 236 & Non \\
\hline 63 & M & 2011 & 22 & 20 & Ant & Intra & 113 & Non \\
\hline 40 & $\mathrm{~F}$ & 2011 & 19.5 & 35 & Les & Extra & 100 & Non \\
\hline 79 & M & 2011 & 19 & 28 & Pos & Extra & 467 & Obstruction \\
\hline 64 & $\mathrm{~F}$ & 2011 & 15.8 & 32 & Les & Intra & 185 & $\operatorname{Non}^{a}$ \\
\hline 70 & $\mathrm{~F}$ & 2012 & 20 & 23 & Les & Extra & 76 & Non \\
\hline 67 & M & 2013 & 24.7 & 16 & Ant & Intra & 86 & Non \\
\hline 73 & $\mathrm{~F}$ & 2013 & 21.1 & 19 & NEJ & Intra & 137 & Non \\
\hline
\end{tabular}

NEJ near esophagogastric junction, Ant anterior wall, Pos posterior wall, Les lesser curvature, Gre greater curvature, Extra extraluminal, Intra intraluminal

${ }^{a}$ Conversion to conventional laparoscopic surgery

On the other hand, SILS has some disadvantages, including conflicts between the laparoscope and instrument, limited movement of instruments, limited organ retraction, and difficulty maintaining the operative field [7]. To address these problems, we constructed the following devices. A suture was placed across the gastric wall at the anal side of the tumor, and the thread was pulled out from the abdominal cavity to enhance the operative field. A second method to prevent the liver obscuring the operating field was to raise the left lateral segment of the liver with a narrow retracting device (Fig. 1).

In conventional laparoscopic surgery, the linear stapler is inserted from the left or right side of the port, whereas in SILS, it is only inserted from the umbilical port. However, stapler insertion may be difficult if the transumbilical space is overcrowded with instruments. Attempts to adjust the resection line by moving the stapler are often unsuccessful. As an alternative, Takata et al. recommended the "move the ground" technique, in which the lesion is brought toward the stapler using an articulated grasper [7]. Despite these improvements, challenges in SILS are often related to the location of the tumor, for example, the need for complicated manipulation by the operator's left forceps to turn over the posterior wall. In the present study, although there were only two patients with GIST on the posterior wall, gastric obstruction following re-operation occurred in one of the two cases. According to the postoperative finding by computed tomography and a contrast medium, we considered the deformation of the stomach occurred due to twisted resection by staple. Stapler use was restricted, and assistance from the left forceps was necessary to turn the gastric posterior wall, which may have caused this severe local complication. In using stapler on tumors on the posterior wall or lesser curvature, handling of the stapler is sometimes difficult. Therefore, we should take care of the resection line not to lead to deformation of the stomach, considering the technical difficulties; SILS for GIST on the posterior wall should be carefully adapted.

In a previous study, we reported the safety of SILS for gastric SMTs near the EGJ, which is challenging due to the risk of EGJ narrowing [8]. During SMT resections, endoscopic observations were used to maintain a sufficient margin from the mucosal side. Furthermore, by opening the lumen of the EGJ using the endoscope as a bougie, the gastric obstruction was prevented. Surgical outcomes of SILS for GISTs located mainly on the anterior wall did not include severe complication. However, because the gastric antrum is narrower than the cardia, it was not possible to adapt SILS in the three cases with GISTs near the pylorus ring. In specific cases, for example, when the tumor location is anterior, SILS may be a safe option for GISTs near the pylorus ring if performed by an experienced surgeon.

Intraluminal tumor is sometimes more difficult than extraluminal tumor because adding seromyotomy and bringing tumor outside of the gastric wall were necessary before resection. As we showed in Table 1, though we could resect the intraluminal tumor as safely as the extraluminal tumor, we took relatively long operative time in SILS of intraluminal tumor compared with that of extraluminal tumor, which may indicate the difficulty of SILS for intraluminal tumor. Considering these results, SILS on extraluminal tumor 
may be feasible; on the other hand, other operative methods such as laparoscopic and endoscopic cooperative surgery may be superior to SILS for intraluminal tumor.

\section{Conclusion}

Based on safety and cosmetic satisfaction, SILS for GIST may become the first choice, especially for tumors located mainly on the anterior wall, including tumors near the EGJ. However, SILS for tumors located on the posterior wall should be carefully adapted due to the necessity for complicated manipulation of the stomach, which may cause injury.

\section{Abbreviations}

EGJ: Esophagogastric junction; GIST: Gastrointestinal stromal tumor;

SILS: Single-incision laparoscopic surgery; SMT: Submucosal tumor

\section{Funding}

None of the authors have anything to disclose.

\section{Availability of data and materials}

All data generated or analyzed during this study are included in this published article.

\section{Authors' contributions}

$\Pi$ TT and SK described and designed the article. SK and SS edited the article. YK supervised the edition of the manuscript. Other remaining co-authors collected the data and discussed the content of the manuscript. All authors read and approved the final manuscript.

\section{Ethics approval and consent to participate}

This study was approved by the Institutional Review Board of Kobe University.

\section{Consent for publication}

Consent has been obtained from all the patients to publish clinical data and images for the purpose of this study.

\section{Competing interests}

The authors declare that they have no competing interests.

\section{Publisher's Note}

Springer Nature remains neutral with regard to jurisdictional claims in published maps and institutional affiliations.

Received: 20 November 2018 Accepted: 13 March 2019

Published online: 29 March 2019

\section{References}

1. DeMatteo RP, Lewis JJ, Leung D, Mudan SS, Woodruff JM, Brennan MF. Two hundred gastrointestinal stromal tumors: recurrence patterns and prognostic factors for survival. Ann Surg. 2000;231(1):51-8.

2. Kwon SJ, Korean Gastric Cancer Study G. Surgery and prognostic factors for gastric stromal tumor. World J Surg. 2001;25(3):290-5. https://doi.org/10. 1007/s002680020040.

3. Demetri GD, Benjamin RS, Blanke CD, Blay JY, Casali P, Choi H, Corless CL, Debiec-Rychter M, DeMatteo RP, Ettinger DS, Fisher GA, Fletcher CD, Gronchi A, Hohenberger P, Hughes M, Joensuu H, Judson I, Le Cesne A, Maki RG, Morse M, Pappo AS, Pisters PW, Raut CP, Reichardt P, Tyler DS, Van den Abbeele AD, von Mehren M, Wayne JD, Zalcberg J, Force NT. NCCN Task Force report: management of patients with gastrointestinal stromal tumor (GIST)--update of the NCCN clinical practice guidelines. J Natl Compr Cancer Netw. 2007;5(Suppl 2):S1-29 quiz S30.

4. Nishida $T$, Hirota $S$, Yanagisawa $A$, Sugino $Y$, Minami M, Yamamura $Y$, Otani Y, Shimada Y, Takahashi F, Kubota T, Subcommittee GG. Clinical practice guidelines for gastrointestinal stromal tumor (GIST) in Japan:
English version. Int J Clin Oncol. 2008;13(5):416-30. https://doi.org/10. 1007/s10147-008-0798-7.

5. Wu SD, Kong J, Su Y, Fan Y. Safety and application of transumbilical singleincision laparoscopic gastrectomy for GIST: SILS in benign gastric disease. Surg Innov. 2013;20(4):365-9. https://doi.org/10.1177/1553350612455224.

6. Kong J, Wu SD, Su Y, Fan Y. Single incision versus conventional laparoscopic resection in gastrointestinal stromal tumors: a retrospective cohort analysis at a single tertiary care center. OncoTargets Ther. 2014;7:995-9. https://doi. org/10.2147/OTT.S62687.

7. Takata A, Nakajima K, Kurokawa Y, Takahashi T, Yamasaki M, Miyata H, Takiguchi S, Mori M, Doki Y. Single-incision laparoscopic partial gastrectomy for gastric submucosal tumors without compromising transumbilical stapling. Asian J Endosc Surg. 2014;7(1):25-30. https://doi.org/10.1111/ases. 12069.

8. Kanaji S, Nakamura T, Yamamoto M, Imanishi T, Suzuki S, Tanaka K, Kuroda D, Kakeji Y. Successful laparoscopic gastric resection and safe introduction of a single-incision technique for gastric submucosal tumors located near the esophagogastric junction. Surg Today. 2015;45(2):209-14. https://doi. org/10.1007/s00595-014-0940-2.

9. Goh BK, Goh YC, Eng AK, Chan WH, Chow PK, Chung YF, Ong HS, Wong WK. Outcome after laparoscopic versus open wedge resection for suspected gastric gastrointestinal stromal tumors: a matched-pair casecontrol study. Eur J Surg Oncol. 2015;41(7):905-10. https://doi.org/10.1016/j. ejso.2015.04.001

10. Pelletier JS, Gill RS, Gazala S, Karmali S. A systematic review and metaanalysis of open vs. laparoscopic resection of gastric gastrointestinal stromal tumors. J Clin Med Res. 2015;7(5):289-96. https://doi.org/10.14740/ jocmr1547w.

11. Deveci U, Barbaros U, Kapakli MS, Manukyan MN, Simsek S, Kebudi A, Mercan S. The comparison of single incision laparoscopic cholecystectomy and three port laparoscopic cholecystectomy: prospective randomized study. J Korean Surg Soc. 2013;85(6):275-82. https://doi.org/10.4174/jkss. 2013.85.6.275.

12. Ceci F, Orsini S, Tudisco A, Avallone M, Aiuti F, Di Girolamo V, Stefanelli F, De Angelis F, Martellucci A, Costantino A, Di Grazia C, Nicodemi S, Cipriani B, Napoleoni A, Mosillo R, Corelli S, Casciaro G, Spaziani E, Stagnitti F. Singleincision laparoscopic appendectomy is comparable to conventional laparoscopic and laparotomic appendectomy: our single center single surgeon experience. II Giornale di chirurgia. 2013;34(7-8):216-9. https://doi. org/10.11138/gchir/2013.34.7.216.

\section{Submit your manuscript to a SpringerOpen ${ }^{\circ}$ journal and benefit from:}

- Convenient online submission

- Rigorous peer review

- Open access: articles freely available online

- High visibility within the field

- Retaining the copyright to your article

Submit your next manuscript at $\boldsymbol{\nabla}$ springeropen.com 